\title{
Flux of Metals in Great Ghost Lake in Taiwan in the Past 2600 Years*
}

\author{
Chen-Tung Arthur Chen and Jen-Kang Wann \\ Institute of Marine Geology and Chemistry, National Sun Yat-Sen University \\ Kaohsiung 80424, Taiwan, China
}

\begin{abstract}
Sediment cores were collected from the remote subalpine Great Ghost Lake in southern Taiwan. Because the lake is anoxic the sediments are well preserved, distinctive past variations can be dated accurately. The vertical distributions of total and acid-leached metal concentrations for aluminum, arsenic, cadmium, cerium, chromium, cesium, copper, iron, magnesium, manganese, nickel, lead, rubidium, strontium, vanadium and zinc are measured and the fluxes determined. The dates of higher fluxes in the past 2600 years seem to correlate with dry spells. Further, trace metal fluxes show a large increase but $\mathrm{Pb}$-206/Pb-207 ratios show a large decrease since 1950, suggesting a significant anthropogenic input.
\end{abstract}

Keywords: trace metals, flux, Great Ghost Lake, Taiwan

\section{Introduction}

With ever increasing population and industrialization, human activities have become the dominant process affecting the global biogeochemical cycling of many trace metals. The amount of material removed from the Earth's crust each year by mining is now of the same order of magnitude as such fundamental geological processes as mountain building, erosion, and oceanic crust formation. Anthropogenic fluxes of many potentially toxic trace metals to the atmosphere have even exceeded the natural fluxes (Shotyk, et al., 1996).

Similarly, the current suite of changes in Taiwan -- population growth, urbanization, and industrialization -- are more profound than any changes that have occured in the past. Notably the rapid industrialization in Taiwan over the past 40 yrs has made air pollution and acid rain major environmental problems. There is the concern that acidified water from acid rain would mobilize metals, thus generating a threat to the health of the public.

For a number of years the authors have been studying the effect of acid rain on lakes in Taiwan. It was concluded that the high mountain lakes are the most threatened hence the distribution of metals in the near-surface sediments of these lakes are likely to be affected (Chen and Hung, 1987; Chen et al., 1988; Wann et al., 1995; Wann and Chen, 1996).

Because of the strong interest in metal fluxes, it is necessary to understand the various pathways.

\footnotetext{
* Received 1997-02-25; accepted 1998-03-27.
} 
The Earth's atmosphere has been known to transport both naturai and anthropogenically mobilized trace elements, among which lead is one of the easiest to study. Atmospheric input has been shown to be dominant for lead (Schaule and Patterson, 1981, 1983; Patterson and Settle, 1987). It is known that aelion anthropogenic lead has been produced from the development of cupellation technology starting about 4500 bp (Settle and Patterson, 1980), and then its production increased markedly in the late 18th century at the beginning of the Industrial Revolution. Around 1940, there was a sharp increase in atmospheric lead concentrations due to lead emissions from automobiles (Murozumi et al., 1969). The industry in Taiwan started to take off about ten years after that.

The anthropogenic source of lead is relatively easy to identify as lead in most ores has $\mathrm{Pb}-$ 206/Pb-207 ratios measurably less than the natural lead of soil and soil-related components (Shirahata et al.,1980). Two widely used methods of reducing the grain-size effects in order to evaluate the natural or anthropogenic sources of metals in the sediments (Kemp and Thomas, 1976; Kemp et al., 1976; Ng and Patterson, 1982; Forstner and Wittmann, 1983; Finney and Huh, 1989) are comparison of the relative abundance with respect to aluminum or the leaching the sample with dilute acid. The iron and manganese oxides, the surface of clay minerals, organic matters and carbonates are the major phases of metal association in sediments. Acid-leached metals represent most of metals in these phases but do not include those in the lattice of clay minerals and rock debris. The latter are of natural origin and are not changed by anthropogenic inputs.

In order to identify the anthropogenic sources it is also useful to compare the recent data with the historical data, which, unfortunately, are lacking in Taiwan. As a result, the authors studied lake sediments deposited over a time span of 2600 yrs. Not only is a baseline thus established, but also natural variations are identified. Finally, the fluxes are calculated in a way similar to the work of Hamilton-Taylor (1979).

\section{Study Area and Methods}

Great Ghost Lake (Ta-Kuei Hu), situated at $22^{\circ} 52^{\prime} \mathrm{N}, 120^{\circ} 51^{\prime} \mathrm{E}$, is a $2150-\mathrm{m}$ high lake and one of the best preserved natural lakes in Taiwan. Because of its isolation there has been little human perturbation. It takes two days to reach this lake by foot from the nearest road. The sediments are well preserved as the lake is not only deep (maximum $40 \mathrm{~m}$, the deepest in Taiwan) but also surrounded by mountains. As a result, the deep water is anoxic most of the year (Chen and Wang, 1990; Wang and Chen, 1990). Little or no wind mixing or bioturbation is expected to have occurred. Sediments that have remained undisturbed in this condition for the past thousands of years thus serve as archives of atmospheric metal deposition.

A home-made gravity corer with plastic barrel was used to collect sediment samples. The cores were sealed by wax immediately after recovery and then opened at the home laboratory by being cut with a fishing line to avoid any contamination by metals (Chen et al., 1993). The water content was determined by freeze drying at $-50^{\circ} \mathrm{C}$. 

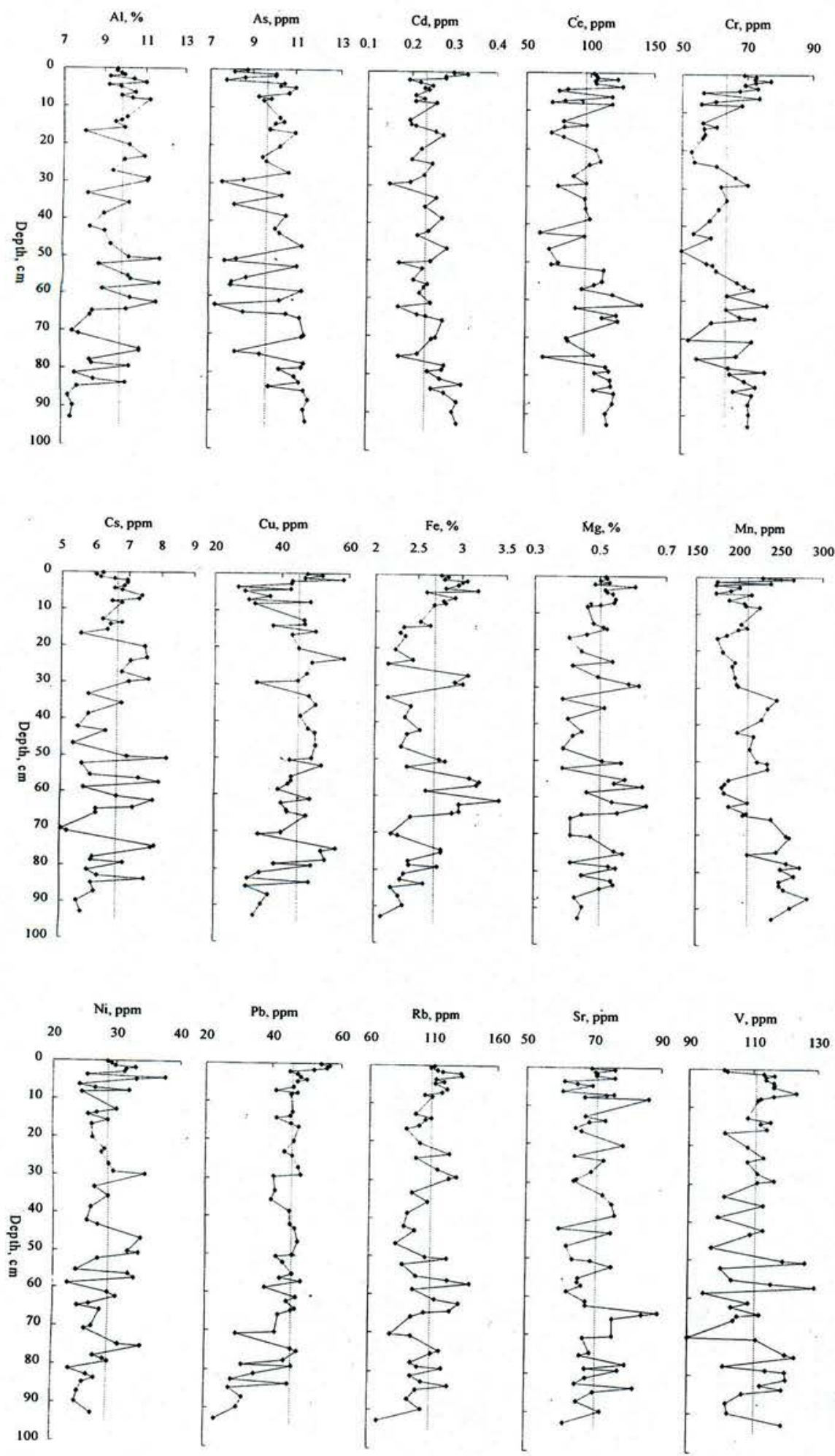

Zn, ppm

$\begin{array}{llll}70 & 90 & 110 & 130\end{array}$

Fig. 1 Vertical distributions of total metal concentrations. 


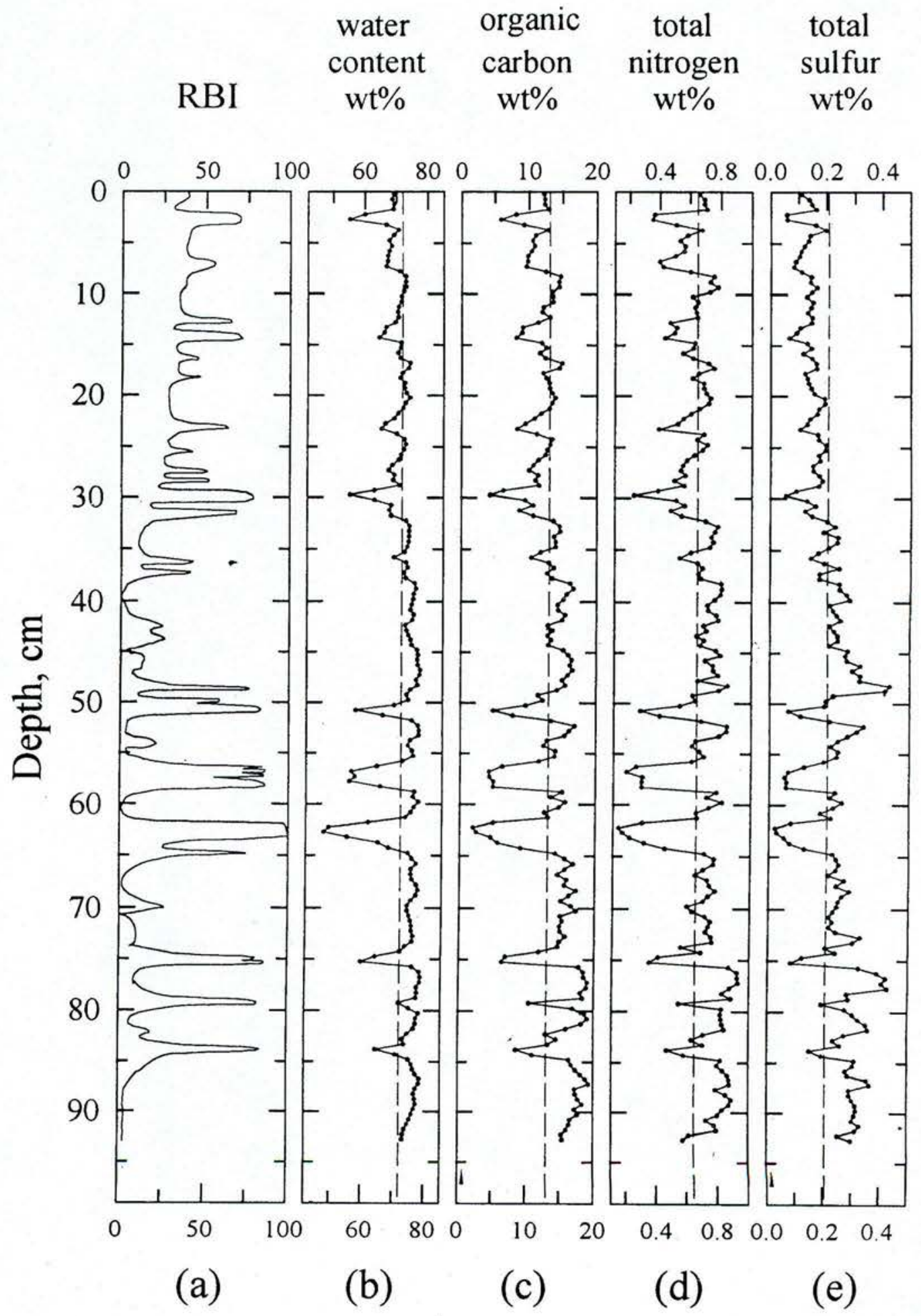

Fig. 2 Vertical distributions of Relative Brightness Index (RBI), water content, organic carbon, total nitrogen and total sulfur (taken from Lou et al., 1997). 

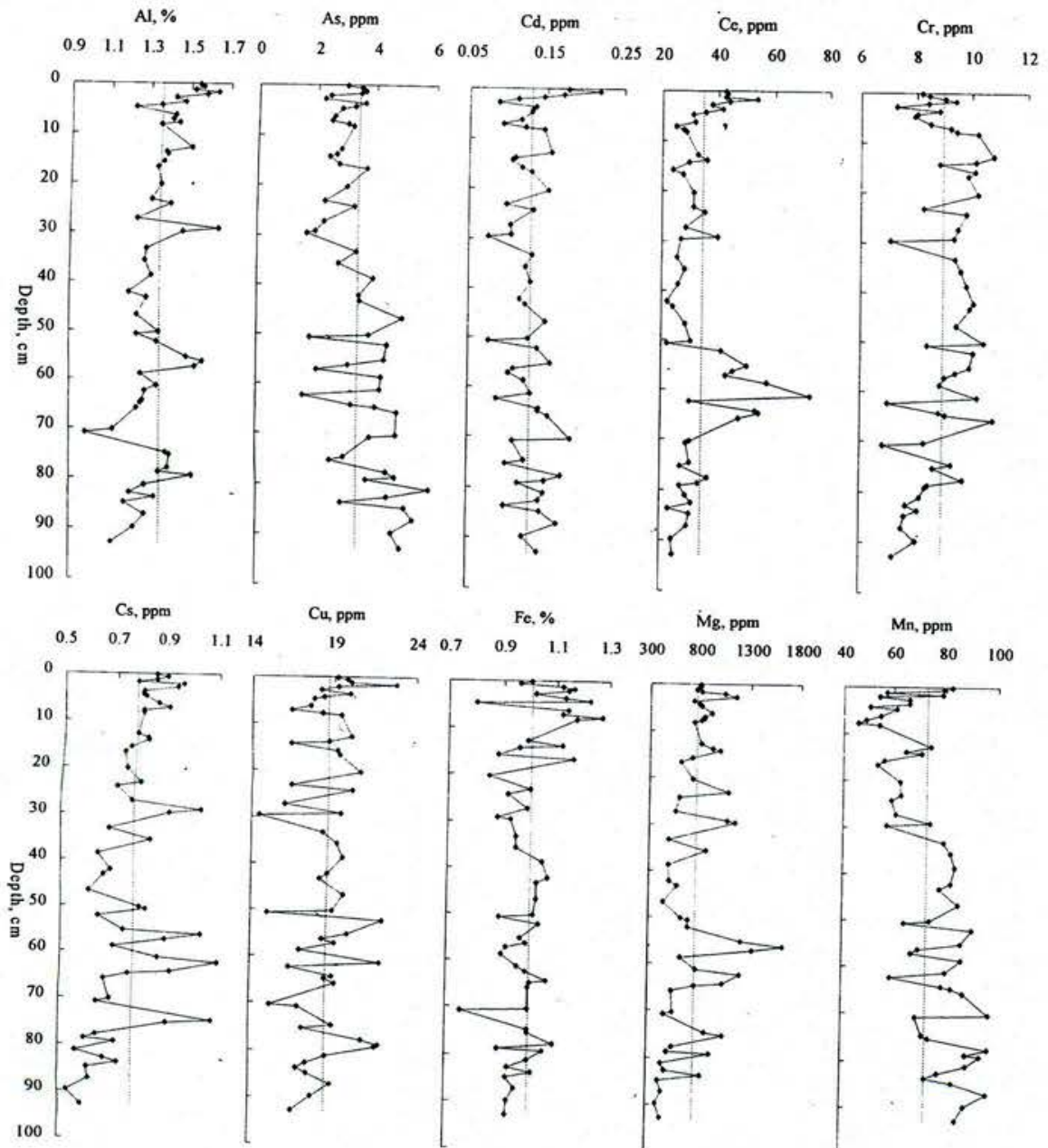

$\begin{array}{lrr}\text { Mn, ppm } \\ 60 \quad 80 & 100\end{array}$
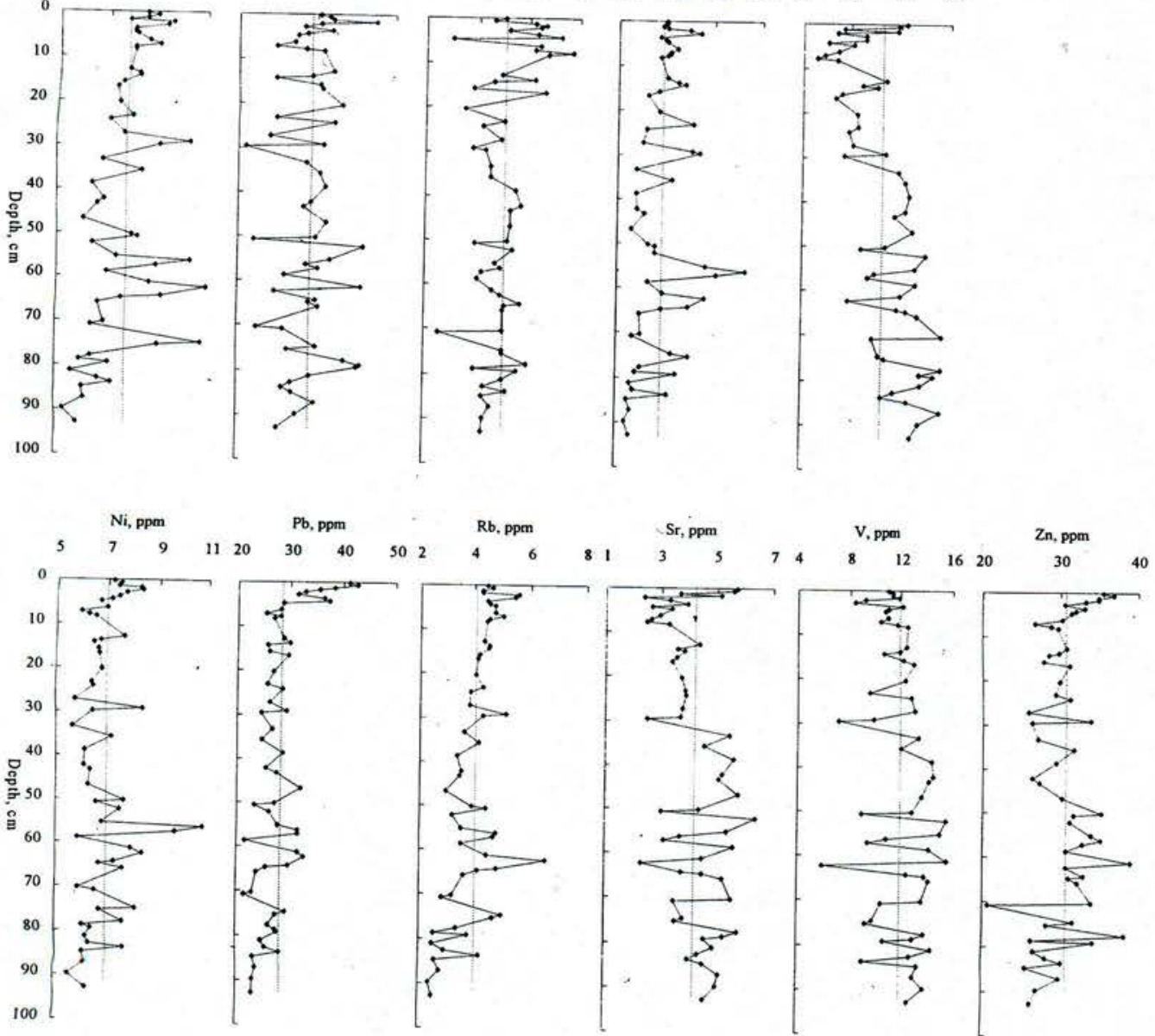

Fig. 3 Vertical distributions of acid leached metal concentrations. 

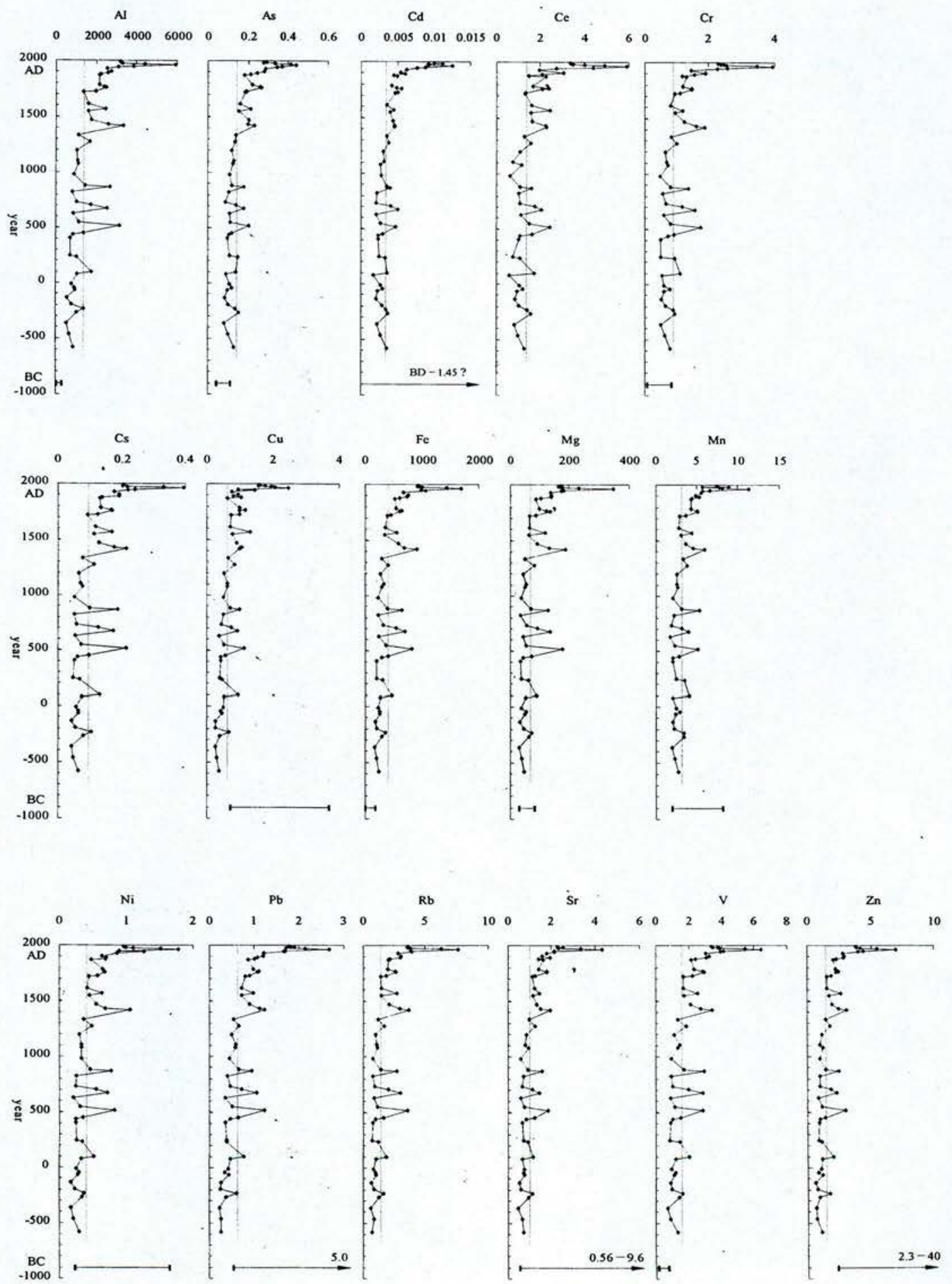

Fig. 4 Fluxes of total metals $\left(\mu \mathrm{g} \cdot \mathrm{cm}^{-2} \cdot \mathrm{yr}^{-1}\right)$ in different years. The total aeolian deposition rates of Wu (1996) are marked at the bottom. 

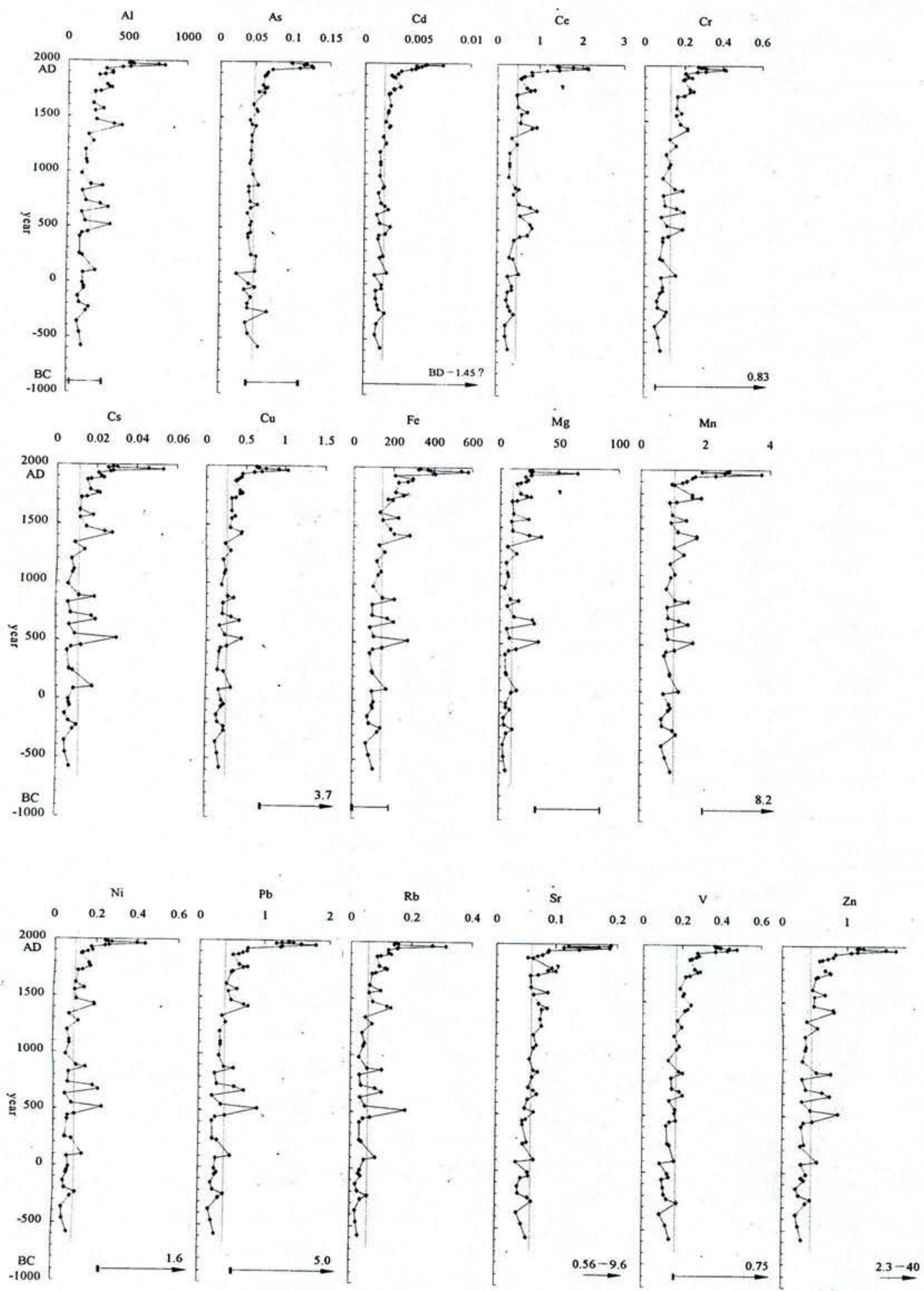

Fig. 5 Fluxes of acid-leached metals $\left(\mu \mathrm{g} \cdot \mathrm{cm}^{-2} \cdot \mathrm{yr}^{-1}\right)$ in different years. The total aeolian deposition rates of $\mathrm{Wu}(1996)$ are marked at the bottom. 

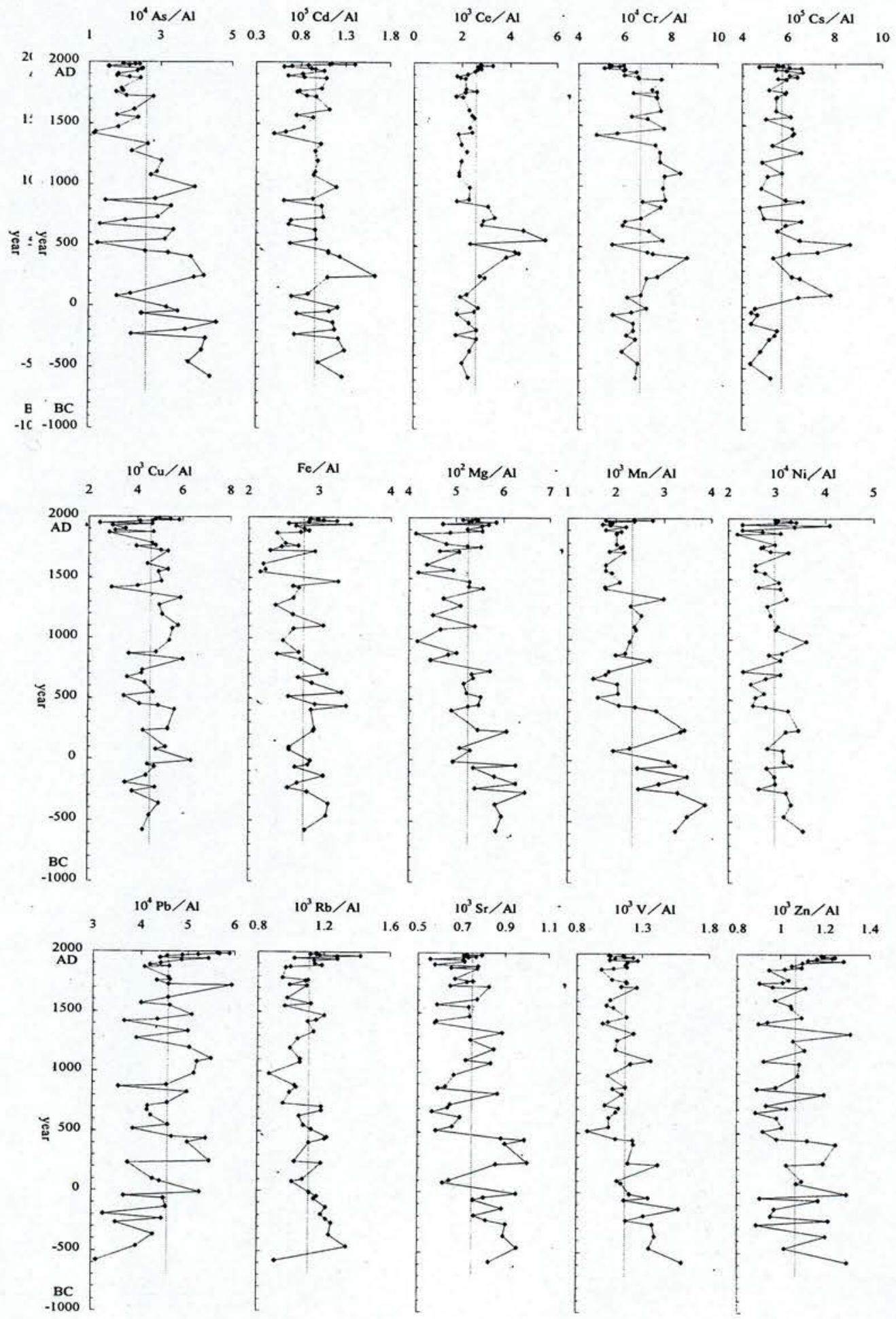

Fig. 6 Fluxes of total metal/Al ratios in different years. 


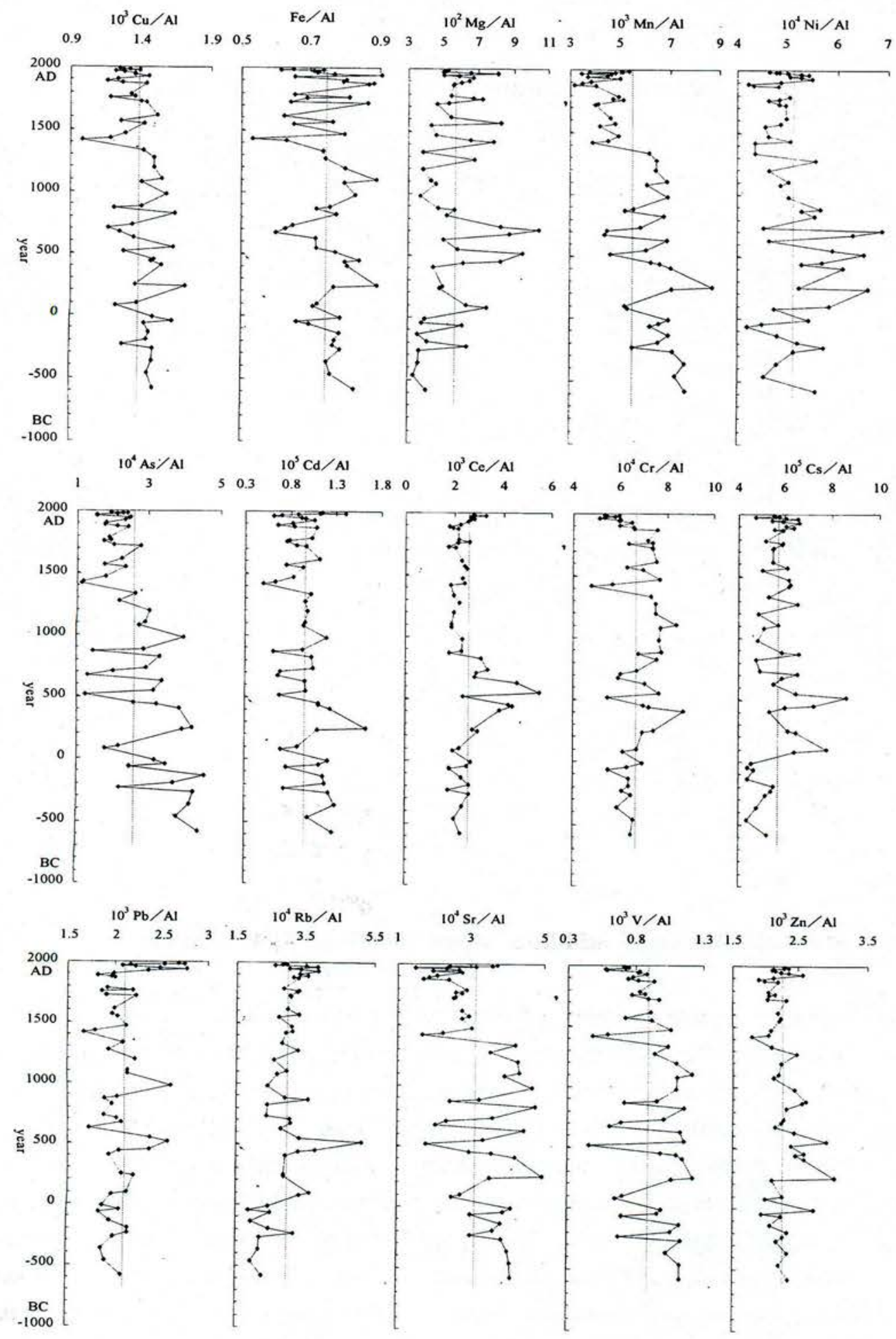

Fig. 7 Fluxes of acid-leached metal/Al ratios in different years. 


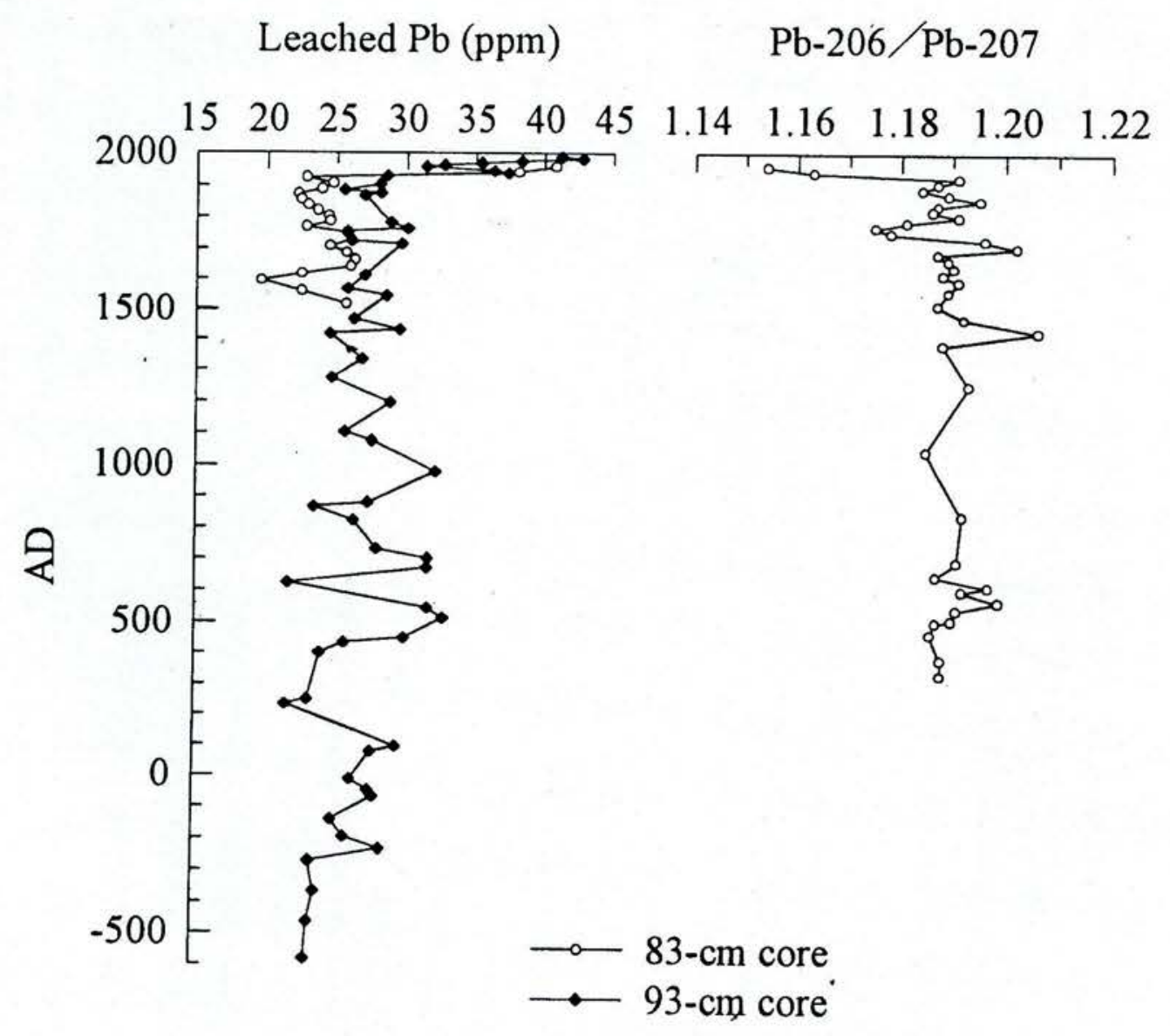

Fig. 8 Vertical distributions of acid-leached lead and $\mathrm{Pb}-206 / \mathrm{Pb}-207$ ratios.

In the leaching procedure, the dried sediment $(0.3 \mathrm{~g})$ was treated with $15 \mathrm{ml}$ of $1.6 \mathrm{~N}$ nitric acid and shaken overnight ( $\mathrm{Ng}$ and Patterson, 1982; Giblin et al., 1990) in a 50-ml centrifuge tube. The leachate was separated by centrifuge and was then removed with a quartz pipette for the measurements of metals and $\mathrm{Pb}-206 / \mathrm{Pb}-207$ ratios. The dry sediments $(0.3 \mathrm{~g})$ for the determination of the total metal content were digested with an acid mixture $\left(40 \% \mathrm{HNO}_{3}, 15 \%\right.$ $\mathrm{HClO}_{4}$ and $20 \% \mathrm{HF}$ ) in pressured bombs or were digested by a microwave system with an acid mixture $\left(42 \% \mathrm{HNO}_{3}\right.$ and $\left.17 \% \mathrm{HF}\right)$. Metals and $\mathrm{Pb}-206 / \mathrm{Pb}-207$ ratios were measured by an ELAN 5000 ICP-MS with a Ryton spray chamber and cross flow nebulizer to which sample solutions were delivered with a peristaltic pump at a flow rate of $1 \mathrm{ml} \cdot \mathrm{min}^{-1}$. Carbon-14 dating was done by both conventional and AMS methods, while $\mathrm{Pb}-210$ dating was done using the method of Chung and Craig (1983) (Chen et al., 1993).

The National Institute for Environmental Studies No.2 Pond Sediment was used to test the 
accuracy of the trace metal determinations. Most of accuracy deviations are less than $10 \%$. A correction was made only when the deviation was larger than $15 \%$. The accuracy of the Pb-206/ $\mathrm{Pb}-207$ measurements could not be checked, but the precision of isotope ratio measurement was roughly $1 \%(\mathrm{n}=5$; Wann and Chen, 1996).

The flux of an element $\mathrm{i}\left(\mathrm{F}_{\mathrm{i}} ; \mu \mathrm{g} \cdot \mathrm{cm}^{-2} \cdot \mathrm{a}^{-1}\right)$ was calculated based on the following equation:

$$
\mathrm{F}_{\mathrm{i}}=\mathrm{S}_{\mathrm{i}} \times \mathrm{D}_{\mathrm{i}}\left(1-\mathrm{W}_{\mathrm{i}}\right)
$$

where $S_{i}\left(\mathrm{~cm} \cdot \mathrm{a}^{-1}\right)$ is the sedimentation rate of sample $\mathrm{i}$ based on the $\mathrm{C}-14$ and $\mathrm{Pb}-210$ dates; $\mathrm{D}_{\mathrm{i}}$ is the bulk density $\left(\mathrm{g} \cdot \mathrm{cm}^{-3}\right)$ of the sample; $C_{i}$ is the concentration $\left(\mu \mathrm{g} \cdot \mathrm{g}^{-1}\right)$ of the element and; $\mathrm{W}_{\mathrm{i}}$ is the water content.

\section{Results and Discussion}

The vertical distributions of 16 total metal concentrations ( $\mathrm{Al}, \mathrm{As}, \mathrm{Cd}, \mathrm{Ce}, \mathrm{Cr}, \mathrm{Cs}, \mathrm{Cu}, \mathrm{Fe}, \mathrm{Mg}$, $\mathrm{Mn}, \mathrm{Ni}, \mathrm{Pb}, \mathrm{Rb}, \mathrm{Sr}, \mathrm{V}$ and $\mathrm{Zn}$ ) are shown in Fig. 1. The values vary a great deal, far more than the possible analytical errors. In order to be certain that these are not caused by sampling error another core was also analyzed. Similar peaks are found (Lou, 1996). In Fig. 2 the authors plotted the Relative Brightness Index (RBI), the water content, the organic carbon content, and the total nitrogen and sulfur contents for the same core. The white laminations (higher RBI) are composed of smaller particles, and have lower water, organic corbon, nitrogen, and sulfur contents. These layers have been suggested to have significant contributions from wind blown material from northern China (Lou et al., 1997). It seems that the peaks in Fig. 1 are related to the RBI peaks. The white laminations at 3,23, 30,51, 58, 63 and $75 \mathrm{~cm}$ have higher concentrations of aluminum, cesium, iron, magnesium, nickel, rubidium and zinc, but lower concentrations of arsenic, cadmium, cerium, manganese and strontium. The first group of metals are mostly from the crust and the second group is more associated with organic matter.

Fig. 3 shows the vertical distributions of acid-leached metals. The peaks also correlate with RBI. In addition, aluminum, cadmium, cerium, copper, lead and zinc show apparent near-surface enrichment, suggesting a possible anthropogenic input. With the help of the $\mathrm{Pb}-210$ and $\mathrm{C}-14$ datings the depth scale can be changed to the age of the sediments. Further, the metal concentrations are converted to fluxes and plotted in Figs. 4 and 5. It can be seen clearly that since about $1350 \mathrm{AD}$, or the onset of the Little Ice Age (Lou, et al., 1997), most metal concentrations started to increase. The highest rate of increase occurs after about $1950 \mathrm{AD}$ when the industrialization started to take off in Taiwan.

Recently Wu (1996) measured total aeolian deposition rate and his results are given at the bottom of Figs. 4 and 5. Our values for magnesium and manganese agree with Wu's data but our results for aluminum, arsenic, chromium and iron are higher than his results. This may be because sediments in Great Ghost Lake also receive inputs from the watershed. However, Wu's results for cadmium, copper, nickel, lead, strontium and zinc are much higher than the background values of ours although the agreement is better for data after1950. His values are higher because his measurements are all in urban areas and these metals are mostly from 
industrial pollution. Strontium may be from sea salt which affects the urban areas in the coastal plains but does not easily reach the $2150 \mathrm{~m}$-high lake.

Since the aeolian particle fluxes also started to increase since $1350 \mathrm{AD}$, as evidenced by the higher RBI value (Fig. 2), the higher metal fluxes are most likely due to the higher rate of longrange transport of crust material. The crust material can best be represented by the aluminum, a relatively conservative element with no significant anthropogenic source. In order to look at other effects, the total metal and acid-leached metal fluxes relative to the aluminum fluxes are plotted in Figs. 6 and 7. The increasing trend since $1350 \mathrm{AD}$ has now largely disappeared, confirming the major contribution of Asian dusts.

Some increasing trends after 1950 , however, still exist, notably for lead. In order to see if this was due to pollution, the authors measured the acid-leached lead in a shorter core collected near the longer core. Both cores show higher fluxes after $1950 \mathrm{AD}$ (Fig. 8). Further, the Pb-210/Pb207 ratios are also plotted in Fig. 8. The ratios decrease after $1950 \mathrm{AD}$, reenforcing the conclusion of an anthropogenic origin of lead near surface.

With the exception of winter time, the hypolimnion of Great Ghost Lake is anoxic with active redox cycles of iron and manganese (Chen and Wang, 1990; Wang and Chen, 1990; Wann and Chen, 1996). Upward migration and diffusion of reduced species could also alter their concentrations, but the effects are probably smaller than variations due to the difference of source material.

Note the onset of the anthropogenic lead increase in Great Ghost Lake was about 1950 AD. Other studies show similar results (Bruland et al., 1974; Skei and Paus, 1979; Shirahata et al., 1980; Ng and Patterson, 1982; Finney and Huh, 1989; Giblin et al., 1990). The onset of the sharp anthropogenic lead increase in Great Ghost Lake also occurred around 1950. The worldwide lead emissions from automobiles since 1940 have probably been important in these sharp increases. Some recent records (Hong et al., 1994; Shotyk et al., 1996), however, indicate that the lead concentration has started to decrease in recent years because the leaded gasoline has been phased out. The record in Great Ghost Lake does not show a decrease in lead concentration near the top yet, perhaps because leaded gasoline in still widely used in Taiwan.

Since Great Ghost lake is located in remote subalpine regions, the anthropogenic metals there must have come from atmospheric fallouts. The high solubility of trace metals in atmospheric particulates was previously noted (Wallace et al., 1977; Hodge et al., 1978; Crecelius, 1980; Ochs and Gatz, 1980; Gatz et al., 1982). It follows that most of the anthropogenic lead in the sediment of Great Ghost Lake was dissolved from aeolian particulates and subsquently sequestered by iron oxides (Wann and Chen, 1996).

\section{Conclusion}

In conclusion, aelion Asian dust particles seem to play a significant role in the flux of metals in Great Ghost Lake. The fluxes are generally higher during dry periods especially since $1350 \mathrm{AD}$. On the other hand, local pollution of certain trace metals seem to be important after $1950 \mathrm{AD}$. 
For instance, the low $\mathrm{Pb}-206 / \mathrm{Pb}-207$ ratios of surface sediments confirm that most of the acidleached lead in the surface sediments of Great Ghost Lake was anthropogenic in origin. Pb-210 and C-14 datings indicated that the onset of large anthropogenic lead increase was about 1950 , probably caused by the worldwide lead emission from automobiles.

\section{Acknowledgements}

The authors wish to thank the Environmental Protection Administration (EPA-86-FA44-09-26 and 47) and the National Science Council (NSC85-2611-M-110-003GP) for supporting this research. The authors also thank Prof. Yu-Chia Chung for assistance in the $\mathrm{Pb}-210$ dating, Prof. Shiuh-Jen Jiang for assistance in the ICP-MS measurements with metals, and Jiann-Yuh Lou and Hsing-Chih Huang for assistance in sampling and analysis.

\section{References}

Bruland, K. W., Bertine, K., Koide, M., and Goldberg, E. D. 1974. History of metal pollution in southern California coastal zone. Environ. Sci. Technol.8: 425-432.

Chen, C. T. A., Hung, J. J., and Wang, B. J. 1988. The past, present, and future acidification of lakes in Taiwan. Institute of Marine Geology Technical Report.No. 2, pp. 131 (in Chinese).

Chen, C. T., and Hung, J. J. 1987. Acid rain and lake acidification in Taiwan. Proceedings, National Science Council.11:436-442.

Chen, C. T. A., and Wang, B. J. 1990. Winter overturning of the anoxic Great Ghost Lake. Proceedings, National Science Council.14:11-15.

Chen, C. T. A., Lou, J. Y., and Wann, J. K. 1993. Preliminary paleo- climatological records from high mountain lakes in Taiwan. Terr. Atm. Oceanic Sci., 4, 321-330.

Chung, Y., and Craig, H. 1983. Pb-210 in the Pacific, the GEOSECS measurements of particulate and dissloved concentrations, Earth and Planet. Sci. Letters, 65, 406-432.

Crecelius, E. A.1980.The solubility of coal fly ash and marine aerosols in seawater. Mar. Chem. 8:245-250.

Finney, B. P., and C-A Huh. 1989. History of metal pollution in the southern California Bight: an update. Environ. Sci. Technol 23:294-303.

Forstner, U., and Wittmann, G. T. W. 1983. Metal pollution in the aquatic environment. SpringerVerlag, Berlin, Heidelberg, New York, Tokyo. pp. 121-130.

Gatz, D. F., Warner, B. K., and Chu, L. C. 1982. Solubility of metal ions in rain water, Am. Chem. Soc. Div. Environ. Chem. Acid Precipitation Symposium, Las Vegas, Nevada, April 1982.

Giblin, A. E., Likens, G. E., White, D., and Howarth, R.W. 1990. Sulfur storage and alkalinity generation in New England lake sediments. Limnol. Oceanogr.35: 852-869.

Gupta, S. K., and Chen, K.Y. 1975. Partitioning of trace metals in selective chemical fractions on nearshore sediments. Environ. Lett..10:129-158.

Hamilton-Taylor, J. 1979. Enrichments of $\mathrm{Zn}, \mathrm{Pb}$ and $\mathrm{Cd}$ in recent sediments of Windermere, England. Environ. Sci. Technol.13.693-697. 
Hodge, V., Johnson, S. R., and Goldberg, E. D. 1978. Influence of atmos- pherically transported aerosols on surface ocean water composition. Geochem. J.12:7-20.

Hong, S., Candelone, J. P., Patterson, C. C., and Boutron, C. F. 1994. Greenland ice evidence of hemispheric lead pollution two millennia ago by Greek and Roman civilizations, Science .265: 1841-1843.

Kemp, A.L.W., and Thomas, R. L. 1976. Impact of man's activities on the chemical composition in the sediments of lakes Ontario, Erie and Huron.Water, Air, and Soil Pollution..5: 469-490.

Kemp, A.L.W., Thomas, R.L., Dell, C.I., and J.-M. Jaquet. 1976. Cultural impact on the geochemistry of sediments in Lake Erie. J. Fish. Res. Board Can.33:440-462.

Lou, J.Y. 1996.The distribution of elements in the sediments of alpine lakes in Taiwan and the paleoclimate, Dissertation, National Sun Yat-sen Univ.PP.194 (in Chinese with Eng. abst.)

Lou, J.Y., C.T.A. Chen and J.K. Wann.1997. Paleoclimatological records of the Great Ghost Lake in Taiwan, Science in China, 40.

Murozumi, M., Chow, T.J., and Patterson., C. C. 1969. Chemical concentrations of pollutant lead aerosols, terrestrial dusts and sea salts in Greenland and Antarctic snow strata. Geochim. Cosmochim. Acta.33:1247-1294.

$\mathrm{Ng}$, A., and Patterson, C. C. 1982. Changes of lead and barium with time in California off-shore basin sediments. Geochim. Cosmochim. Acta.46:2307-2321.

Ochs, H. T., and Gatz, D. F. 1980. Water solubility of atmospheric aerosols. Atmos. Environ.14: 615-616.

Patterson, C.C., and Settle, D. M. 1987. Review of data on eolian fluxes of industrial and natural lead to the lands and seas in remote regions on a global scale. Mar. Chem.22:137-162.

Schaule, B. K., and Patterson, C.C. 1981. Lead concentrations in the northeast Pacific: evidence for global anthropogenic perturbations. Earth Planet. Sci. Lett..54:97-116.

Schaule, B. K., and Patterson, C.C. 1983. Perturbations of the natural lead depth profile in the Sargasso Sea by industrial lead. In: C.S.Wong, E. Boyle, K.W. Bruland, J.D. Burton and E.D. Glodberg (Editors), Trace Metals in sea Water, NATO Conf. Ser. IV: Marine Sciences, Vol. 9, Plenum Press, New York. pp. 487-503.

Settle, D. M., and Patterson, C.C. 1980. Lead in Albacore: Guide to lead pollution in Americans. Science.207:1167-1176.

Settle, D. M., and Patterson, C. C. 1982. Magnitudes and sources of precipitation and dry deposition fluxes of industrial and natural leads to the North Pacific at Enewetak. J. Geophys. Res.87: 8857-8869.

Shirahata, H., Elias, R.W., Patterson, C. C., and Koide, M. 1980. Chrono- logical variations in concentrations and isotopic compositions of anthropogenic atmospheric lead in sediments of a remote subalpine pond. Geochim. Cosmochim. Acta, 44:149-162.

Shotyk, W., Cheburkin, A. K., Appleby, P. G., Fankhauser, A., and Kramers, J. D. 1996. Two thousand years of atmospheric arsenic, antimony, and lead deposition recorded in an ombrotrophic peat bog profile, Jura Mountains, Switzerland, Plant. Sci. Lett. 145, E1-E7. 
Skei, J., and Paus, P.E. 1979. Surface metal enrichment and partitioning of metals in a dated sediment core from a Norwegian Fjord. Geochim. Cosmochim. Acta.43:239-246.

Wallace, G.T., Hoffmann, G. L., and Duce, R. A. 1977. The influence of organic matter and atmospheric deposition on the particulate trace metal concentrations of northwest Atlantic surface seawater. Mar. Chem..5:143-170.

Wang, B. J., and Chen, C.T.A. 1990. Geochemistry of the anoxic Great Ghost Lake. Proceedings, National Science Council.14:16-20.

Wann, J. K., Chen, C.T.A., Lin, Z. M., and Jiang, S. J. 1995. Sources and sinks of lead and other trace metals enriched in the surface sediments of remote subalpine lakes in Taiwan, Terr. Atm. Oceanic Sci.6:379-392.

Wann, J. K., and Chen, C.T.A. 1996. Distribution of trace metals in the surface sediments of two pristine subalpine lakes in Taiwan, Chemistry and Ecology.12: 67-89.

Wu, Y. L. 1996. Investigation of total acid deposition and analysis of various mediums, Environ. Prot. Adm. Report.52-55 (in Chinese). 